\title{
Linus Carl Pauling (1901-1994)
}

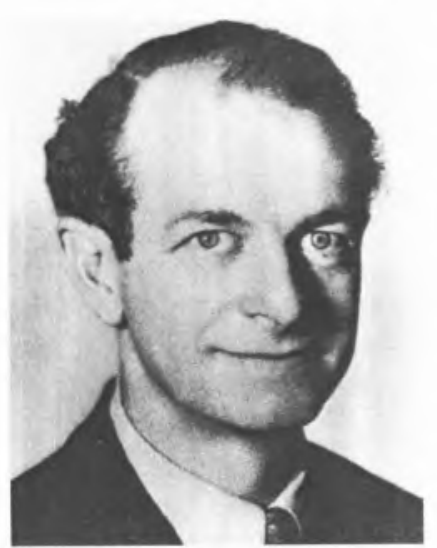

Vítima de um cancro, faleceu em Agosto o grande químico americano Linus Pauling. A sua actividade excepcional traduziu-se em mais de 350 artigos e vários livros de grande repercussão, entre os quais os clássicos Introduction to Quantum Mechanics (1935; com E.B. Wilson; 17 reimpressão em 1981), e The Nature of the Chemical Bond and the Structure of Molecules and Crystals (1939, 1940, 1960; com 16.000 citações entre 1955 e 1983).

0 interesse de Pauling pela Química foi despertado aos 13 anos, ao encontrar em casa um livro de Quimica. Em consequência disto, veio a montar um pequeno laboratório na cave. Doutorou-se pelo California Institute of Technology em 1925, com a tese "The determination with $\mathrm{X}$-rays of the Structure of Crystals". No seu pós-doutoramento, em 1926 , percorreu a Europa, contactando com Bohr, Sommerfeld, Schrödinger, Heitler e London, numa altura em que a Mecânica Quântica acabava de ser desenvolvida. Pauling foi um dos primeiros a aplicá-la à Química, sendo notáveis os seus trabalhos sobre a estrutura e propriedades moleculares, e em particular sobre a ligação química (teoria do enlace de valência, conceitos de hibridação e ressonância, ligação de hidrogénio, ligação metálica, ligação peptídica e estrutura proteica, etc.).

Veio a receber o Prémio da Química de 1954 "pelos seus trabalhos sobre a natureza da ligação química, com aplicação à determinação da estrutura de substâncias complexas". Pauling recebeu também o Prémio Nobel da Paz em 1962, pelos seus esforços a favor da supressão de ensaios de armas nucleares (e.g. o livro No More War, 1958). Foi até hoje 0 único galardoado com dois Prémios Nobel não partilhados. Mais recentemente, tornou-se notado pela sua defesa pública da incorporação de doses maciças de vitamina $C$ na dieta quotidiana, que praticava aliás em si próprio. Caso notável de Iongevidade. permaneceu cientificamente activo até ao fim. Recorde-se, por exemplo, o seu artigo aos 91 anos sobre a ligação química (L. Pauling, $J$. Chem. Educ. 69 (1992) 519).

\section{Joseph Chatt \\ $\mathrm{N}$ o t a b i o g r áf i c a ARMANDO POMBEIRO*}

Nascido em 1914 em County Durham (Inglaterra), de uma familia de agricultores, 0 seu interesse pela Ciência cedo se manifestou, pela curiosidade evidenciada, quando ainda criança, nas visitas a uma fábrica de artigos em aço guiadas por um tio que ai trabalhava, como quimico, tendo então assistido, e.g. à conversão de água em "vinho" (adição de solução alcalina à fenolftaleína) e a trabalhos de sopragem de vidro, e tendo-se entusiasmado pela electricidade ao ponto de aplicar (quando ainda frequentava a escola primária de uma pequena aldeia, em Welton, Cumberland) uma célula electroquímica, de dicromato com cátodo de zinco, na iluminação eléctrica do seu quar- relação à zona mineralizada de Caldbeck Fells, além da influência do seu tio e da experiência escolar. Interessado não só em coleccionar minerais como também na sua identificação e análise, recorda ainda que 0 seu tio chegou a fazer-lhe a análise quantitativa completa de um mineral silicatado, enquanto que 0 seu professor de quimica o introduzia em métodos de análise qualitativa. Mais tarde chegou a montar em casa o seu próprio laboratório (o qual, no Inverno, funcionava no seu quarto) e, numa noite, no pátio desocupado observou 0 efeito da acção do sódio sobre água régia (!).

Curiosamente a sua admissão ao ensino secundário decorreu tardiamente, já com a idade de catorze anos, pois o seu Pai, já idoso, julgava que assim seria necessário. Frequentou então, com assinalável sucesso, a Nelson School, em Wigton (tendo recuperado consideravelmente 0 atraso em relação aos

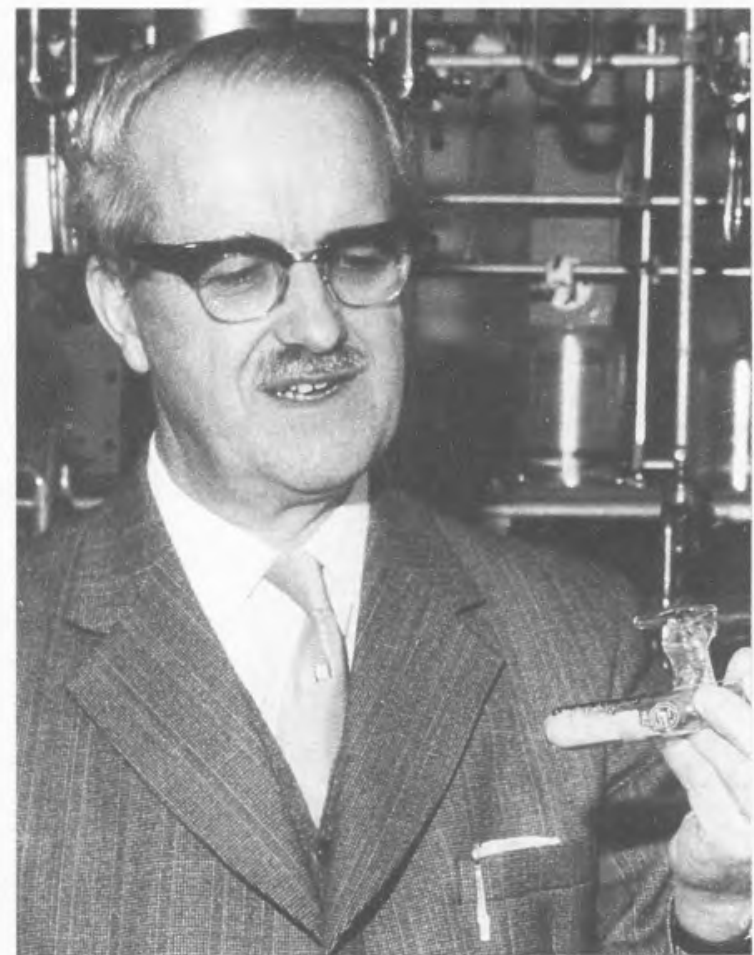

Professor Joseph Chatt ( 1914 - 1994). da sua idade fazendo em 2 anos os estudos de 4 anos), após 0 que foi admitido no Emmanuel College, em Cambridge, através dos bons ofícios de alguns dos seus professores, um dos quais conseguiu a sua admissão neste prestigioso colégio, apesar de todas as vagas terem então já sido tomadas. Ai desenvolveu também o seu trabalho de doutoramento, sob a orientação de F.G. Mann, sobre complexos fosfínicos e arsénicos de paládio 


\section{0 ensino em Países Francófonos}

\section{Colóquio Internacional sobre os 10 anos do CIFEC}

Dez anos passam depressa, mas é já algum tempo para mostrar a experiência do trabalho do CIFEC $^{1}$. Regozijamo-nos, assim, com este centro, criado em 1984, sob o impulso da UNESCO, com sede em Montpellier, e que desenvolve 0 seu trabalho em paises francófonos, nomeadamente nos da África do Norte e África Central. Em vários dos trabalhos e conferências organizados pelo CIFEC estiveram presentes representantes de
Portugal, como por exemplo em 1988 no "atelier" de construção de material experimental, em Valência; em 1989 nas JIREC ${ }^{2}$, em Montpellier; em 1990 na Escola de Outono, na Grande Motte, sobre Investigação em Didáctica da Química; e em 1992 no $1^{\circ}$ ECRICE $^{3}$, no âmbito das actividades da $\mathrm{FECS}^{4}$, em Montpellier.

Com este Colóquio pretendeu-se: fazer 0 balanço dos dez anos de actividade; reforçar a rede existente e desenvolver acçōes de cooperação, elucidar sobre o papel da língua no ensino das ciências e discutir um plano da acção para o CIFEC para os próximos anos. Ao longo de três dias houve conferências plenárias e mesas redondas com especialistas de educação e responsáveis de organismos internacionais. A publicação das Actas será feita em breve.

(1) CIFEC - Centre
Intemational Francophone pour l'Éducation en Chimie

(2) JIREC - Joumées Internationales sur la Recherche en Éducation en Chimie

(3) ECRICE - European Conference on Research in Chemical Education

(4) FECS - Federation of European Chemical Societies

Mariana P.B.A. Pereira Dep. Educação-Fac. Ciências - Univ. Lisboa [tendo então também sintetizado, e.g, a o-fenilenobis (dimetilarsina), que se tornaria tão bem conhecida] o que viria a influenciar significativamente a sua carreira científica.

Após 0 seu doutoramento e durante a II Grande Guerra, trabalhou na indústria, no Woolwich Arsenal (Londres) (onde tentou descobrir um substituto para a nitroglicerina) e na Peter Spence \& Sons Ltd. (tendo então procurado melhorar o rendimento da redução electrolítica do tetracloreto de titânio). Porém, a sua simpatia pela investigação pura, não circunscrita pelos interesses comerciais a curto prazo, levou- 0 a que, após o fim da guerra, e usufruindo de uma bolsa de investigação de pós-doutoramento da Imperial Chemical Industries, Ltd (I.C.I.), se tenha transferido para o Imperial College (Londres), onde, no entanto, sobretudo em resultado das fortes contenções de despesas e da falta de material indispensável à investigação, teve uma estadia frustrante (ca 9 meses). Procurou então emprego na própria I.C.I., tendo ficado responsável pelo departamento de química inorgânica nos novos laboratórios de investigação fundamental desta empresa, conhecidos como "The Butterwick" e, mais tarde, como "The Akers", situados em "The Frythe", uma casa de campo nas proximidades de Welwyn em Hertfordshire.

Curiosamente, após ca. de treze anos da sua criação, 0 departamento de química inorgânica de J. Chatt converteu-se num grupo de investigação da Divisão de Produtos Quimicos Orgânicos Pesados da mesma empresa. Esta alteração, embora determinada por razōes económicas, envolvendo a transição do campo inorgânico para 0 orgâni$\mathrm{Co}$, ilustra a versatilidade $\mathrm{e}$ a vastidão da formação científica de J. Chatt que bem reconheceu a fluidez ou 0 artíficio da linha de separação entre estes ramos da quimica e a importância da sua interdisciplinaridade.

Foi nos laboratórios da I.C.I. que J. Chatt desenvolveu, durante vários anos, uma investigação pioneira do mais elevado mérito em química de compostos de metais de transição sendo um dos maiores impulsionadores (considerado até, por muitos cientistas, como o principal promotor) do renascimento da química inorgânica ou da criação da química de coordenação moderna, em particular o ramo da química organometálica de metais de transição, actualmente de grande relevância cientifica $e$ interesse industrial.

Entre as contribuições básicas e mais conhecidas de $\mathrm{J}$. Chatt, realizadas durante 0 periodo de estadia na I.C I., para o desenvolvimento daqueles ramos da quimica, figuram as seguintes (i) a explicação, devidamente fundamentada, proposta em 1953 (com L.A. Duncanson e inspirada também em estudos de M.J.S. Dewar sobre complexos de prata), da coordenação das olefinas a metais de transição (envolvendo não só uma componente de doação electrónica, para 0 metal, da orbital- $\pi$ da olefina, como ainda uma componente de retrodoação de uma orbital preenchida do metal para a orbital vazia $\pi *$ da olefina), conhecida como modelo de ChattDuncanson-Dewar, depois generalizada a uma diversidade de sistemas com ligandos insaturados, incluindo os metalocenos: (ii) a classificação (com Ahrland e Davies) de iões metálicos em grupos (classes a e $b$ ) de acordo com a sua afinidade ralativa por tipos de átomos doadores dos ligandos, de importância na compreensão da estabilidade de complexos, e que posteriormente conduziu (R. Pearson) ao conceito (menos preciso mas de maior aplicação) de dureza ou maciez de ácidos ou bases); (iii) 0 alargamento do uso de fosfinas e arsinas em química de coordenação, designadamente 0 reconhecimento da sua capacidade de estabilização de uma diversidade de complexos em particular de tipos novos cuja sintese se julgava impossivel (e.g., certos complexos hidretos, alquilos ou arilos, e, mais tarde, compostos de diazoto) (a química de complexos fosfinicos tornou-se um dos ramos mais activos da química de coordenação e organometálica); (iv) contribuições no estudo do efeito e da influência trans de ligandos em complexos.

0 reconhecimento do mérito e da importância da investigação de J. Chatt, na I.C.I., são bem patentes na sua eleição, em 1961, como "Fellow" da Royal Society (F.R.S.), aproximadamente na mesma altura em que 0 seu departamento de química inorgânica transitava para 


\section{$1^{0}$ Congresso Ibérico sobre Contaminação e Toxicologia Ambiental}

0 Instituto do Ambiente e Vida vai promover na Universidade de Coimbra, de 8 a 11 de Dezembro de 1994, o $1^{0}$ Congresso Ibérico sobre Contaminação e Toxicologia Ambiental. A sua realização resulta de contactos havidos entre vários grupos de investigação, de Portugal e Espanha, nomeadamente após a realização do $1^{\circ}$ Congresso Mundial da SETAC (Society of Environmental Toxicology and Chemistry), efectuado no Centro de Congressos da FIL - Lisboa, em Março de 1993, em que participaram 880 congressistas, de 47 paises. Sistemas em Stress é
0 tema geral deste $1^{\circ}$ Congresso Ibérico, sendo abordados principalmente os problemas de Contaminação e Toxicologia Ambiental das Águas Subterrâneas, das Águas Interiores (albufeiras, lagoas, rios), do Ar (contaminação atmosférica), nos Ecossistemas Terrestres e em Estuários e Zonas Costeiras.

0s Congressos Ibéricos sobre Contaminação e Toxicologia Ambiental, que agora se iniciam, terão uma periodicidade bienal e serão realizados alternadamente em Portugal e em Espanha. Pretende-se que constituam um fórum Luso-Espanhol para apresentaçã̃o, confronto e debate de temas, estudos e soluções para problemas relacionados com a Contaminação e Toxicologia Ambiental, promovendo a divulgação das actividades de I\&D efectuadas em Portugal e Espanha e potenciando a criação de sinergias entre as diversas equipas dos dois países. Dirigem-se aos grupos profissionais relacionados com a temática da Contaminação e Toxicologia Ambiental (Biólogos, Engenheiros Agrónomos, do Ambiente, Químicos e Civis, Geólogos, Físicos, Médicos, Químicos, Veterinários, etc), que desenvol- vam a sua actividade profissional nos vários sectores aos quais interessam os temas a debater (Autarquias, Empresas de Consultoria, Indústrias, Institutos Públicos ou Privados de I\&D, Organismos Governamentais, ONG, Universidades).

\section{Contacto:}

Prof. Dr. Amadeu M.V.M. Soares Instituto do Ambiente e Vida Universidade de Coimbra

Dept. Zoologia

3049 COIMBRA CODEX

PORTUGAL

Tel.: 351-(0)939-34729

Fax: $351-(0) 39-26798$
(..) o domínio da química orgânica.

Porém, em 1962, com a decisão da I.C.I. de vender as suas instalações "The Frythe", por motivos financeiros, e de dispersar o seu pessoal pelas várias Divisōes, J. Chatt decidiu aceitar o convite do "Agriculture Research Council" (A.R.C.) para estabelecer uma unidade de investigação interdisciplinar para 0 estudo da fixação biológica do azoto, por quimicos, bioquími$\cos$, microbiologistas e, mais tarde, geneticistas moleculares. Foi assim criada, na recém-fundada Universidade de Sussex, a Unidade de Fixação de Azoto (Nitrogen Fixation Unit) da qual, coadjuvado pelo microbiologista J. Postgate como Vice-Director, J. Chatt foi o primeiro Director, tendo então (1964) também sido nomeado Professor daquela Universidade.

Esta Unidade de investigação, na dependência do A.R.C., embora em estreita colaboração com a School of Molecular Sciences da Universidade, cedo se afirmou, sob a liderança de J. Chatt, como um centro proeminente de investigação e 0 mais prestigia- do no dominio competitivo para que fora criado. Da interacção entre a Unidade de Fixação de Azoto e aquela Escola (na qual funcionava também um laboratório de investigação dirigido pela Unidade e na qual leccionavam, a título honorário, alguns dos investigadores da mesma) resultou um franco beneficio mútuo que contribuiu eficazmente para a rápida promoção da reputação internacional das duas instituições.

Embora ainda dentro do espirito de inter- e multi-disciplinaridade em que fora criada aquela Unidade, uma extensão apreciável da sua investigação efectuada no referido laboratório da Universidade (e.g., por alunos de pós-graduação orientados por membros da Unidade) dirigia-se segundo temas periféricos (ou menos óbvios) ao problema central da Fixação de Azoto. No entanto, diversos progressos neste domínio só foram possíveis com base nos resultados obtidos pelo grupo da Universidade, como J. Chatt reconheceu.

Entre os desenvolvimentos atingidos pela Unidade (considerada na globalidade) figuram (i) a extensão da química de complexos de metais de transição em baixos estados de oxidação, (ii) a activação química ou electroquímica, controlada, do diazoto (com conversão sequencial em produtos tais como amoníaco, hidrazina ou derivados organoazotados) e a sua interpretação mecanística, e (iii), no campo biológico, a investigação sistemática da cinética das reacções da nitrogenase e a transferência do gene fixador de azoto da K. pneumoniae para a E. coli, com significado importante em biologia molecular. Pela excelência do seu trabalho à frente da prestigiosa Unidade de Fixação de Azoto, J. Chatt foi nomeado, em 1978, "Commander of the Most Noble Order of the British Empire (C.B.E.)", tendo-se jubilado em 1980.

Em 1981 recebeu o prémio de Química da Fundação Wolf (Israel), o mais prestigiado após o prémio Nobel com 0 qual, na opinião de muitos cientistas, ele também deveria ter sido agraciado.

Entre outras distinções ou cargos profissionais que desempenhou, podem citar-se os seguintes: foi 0 primeiro
Presidente (1972) da "Dalton Division" (Divisão de Química Inorgânica) da Chemical Society, Presidente da Secção B (Química) da "British Association for the Advancement of Science", fundador (1950) da bem conhecida série de Conferências Internacionais de Química de Coordenação (I.C.C.C.) que dirigiu durante 9 anos, membro da Comissão de Nomenclatura de Química Inorgânica da I.U.P.A.C., Membro da "American Chemical Society" (desde 1961), da "New York Academy of Sciences", da "American Academy of Arts and Sciences" e de várias outras Academias (incluindo a Academia das Ciências de Lisboa, tendo sido eleito em 1978, com a qual colaborou na organização de um colóquio e na edição de um livro sobre "New Trends in the Chemistry of Nitrogen Fixation", publicado em 1980 por esta Academia e pela Academic Press e depois traduzido em língua russa), recebeu a "Davy Medal" da "Royal Society" (1979), a medalha de ouro Chandler da Universidade de Columbia, Nova York, diversas medalhas da "Royal Society of 


\section{A Europa e a sociedade de informação global}

0 grupo de informação da Comunidade apresentou em Junho na cimeira europeia de Corfu, um importante documento sobre o papel da Europa na sociedade da informação global. Este relatório, preparado propositadamente para a cimeira, desafia os países europeus a liderar a revolução nas comunicações transformando-a em energia útil para beneficiar a ciência, a economia, as relações de trabalho e 0 emprego, 0 progresso e a qualidade de vida dos cidadãos. A sociedade da informação, já em mudança acelerada, implica grandes mudanças sociais que exigem um aumento da eficiência das organizações sociais e económicas, reforçando deste modo a coesão.

As recomendações do relatório são ambiciosas e insistem numa verdadeira democratização no acesso às modernas tecnologias da comunicação; propondo novas oportunidades para os criadores, novas oportunidades para as regiões defenderem e afirmarem a sua identidade cultural, maior eficácia nos serviços da administração públi- ca, maiores mercados de equipamento de software, computadores e produtos da indústria electrónica.

0 grupo de trabalho, liderado por Martin Bangeman. recomenda ainda ao Conselho Europeu que lidere e fomente uma rede trans-europeia de comunicações de serviços básicos, tais como o correio electónico, serviços video, redução de tarifas das comunicações por satélite, o teleworking, o ensino à distância, bases de dados disponiveis para universidades $\mathrm{e}$ centros de pesquisa, redes de comunicação hospitalares e da administração pública, informaçẩo de tráfego aéreo e rodoviário nas cidades, entre outros serviços de acesso facilitado.

\section{Ozono \\ em Worshop nos EUA}

A $4^{\mathrm{a}}$ US/FRG/EU works. hop sobre o problema fotoquimico do ozono e o seu controle numa escala urbana, regional e global, decorreu entre 13 e 17 de Junho em Charleston, па Carolina do Sul, Estados Unidos. Em agenda estiveram debates sobre os efeitos da poluição fotoquímica do ar e os esforços para controlar o ozono. Discutiram-se ainda pesquisas no campo da fotoquímica atmosférica, inventários de emissões, análise instrumental de poluentes e modelos de qualidade do ar.
Chemistry", foi distinguido com várias "Lectureships" (Tilden, Nyholm, Organometallic Chemistry, Liversidge) e outras distinçōes por diversas instituiçōes cientificas, tais como a Academia das Ciências Soviética, o Instituto Kurnakov de Química Geral e Inorgânica (Medalha Chugaev e diploma), e recebeu graus honorários pelas Universidades de Lund, Pierre e Marie Curie (Paris), East Anglia e Sussex. Foi-lhe ainda atribuida (1978) uma "Honorary Fellowship" pelo Emmanuel College, seu antigo colégio, com 0 qual manteve sempre laços de grande amizade, 0 que 0 deixou particularmente sensibilizado.

0 seu espólio científico inclui cerca de 400 artigos e os seus interesses compreendiam também a numismática, a arte $\mathrm{e}$ 0 gosto por viajar.

J. Chatt foi um dos maiores quimicos deste século, meticuloso, sempre em busca da perfeição, não só com uma formação científica abrangente $e$ multidisciplinar como ainda dotado de uma intuição química rara.

Com uma dimensão humana invulgar, uma personali- dade digna, de educação esmerada mas sem vaidades (embora consciente do seu valor), mentalidade aberta, de trato afável com pessoas de todos os niveis intelectuais ou sociais, soube ainda levar uma vida familiar feliz, tendo tido a ventura e 0 mérito de encontrar na sua esposa Ethel 0 apoio, a tranquilidade e o equilibrio indispensáveis à sua expressão completa em termos humanos, morais e profissionais. J. Chatt foi (e será) um exemplo de vida a seguir $\mathrm{e}$ a inspiração cientifica a não perder.

Assim foi o homem e 0 cientista J. Chatt, feliz por ter vivido ao longo do que considerou terem sido alguns dos melhores anos da ciência, especialmente da química inorgânica, mas crítico da política actual da "relevância" (em termos de interesses comerciais ou nacionais ou, possivelmente,das chamadas "áreas prioritárias") dos temas da investigação científica ("the legislators talk of relevance, but the most important discoveries of science were rarely planned" e ".. the scientist who discovers... may never know the value or extent of what he has found" [1]) e da morosa burocracia enganadoramente favorável à parcimónia das instituiçōes financiadoras e fortemente restringente da actividade nobre de investigação ("... now scientists spend almost as much, if not more, time foraging for money to support their work than they do in creative science" $e$ "... if you want really good new science, choose a dedicated scientist and let him get on with it. Do not keep pestering him for reports and programmes"[1]).

Será que as novas gerações de governantes, gestores de ciência, empresários e cientistas conseguirão contrariar aquelas tendências, a bem da extensão do período de ouro do progresso da ciência de qualidade ("a really good new science") em favor de uma ciência de pseudo-relevância ou pseudoprioritária, burocratizada e condicionada por parâmetros de menor qualidade cientifica?

\section{BIBLIOGRAFIA}

1 - "Interview of Joseph Chatt (A Celebration of Inorganic Lives)", G.J Leigh, Coord. Chem. Rev., 108 (1991) $1-25$
2- C. Eaborn, "Professor Joseph Chatt, CBE, FRS, 6 Nov, 1914 19 May 1994"; XV|th Internat. Conference on Organometallic Chemistry, Univ. Sussex, Brighton, 1994.

3 - W. A. Campbell e N.N. Greenwood, "Contemporary British Chemists", Taylor \& Francis Ltd, Londres, 1971, p. 53.

\section{AGRADECIMENTOS}

0 autor agradece ao Dr. R.L. Richards e ao Prof. G. J. Leigh (Nitrogen Fixation Laboratory, Univ. Sussex) a disponibilização de alguns dados biográficos e a fotografia que se insere neste texto, bem como ao Prof J.J.R. Fraústo da Silva (I.S.T.) 0 estabelecimento do contacto com o Prof J. Chatt e a viabilização das condições que permitiram ao autor, em 1973, viajar para o seu laboratório e aí desenvolver o trabaIho de investigação até ao doutoramento.

'Centro de Química Estrutural, Complexo I, Instituto Superior Técnico,

Av. Rovisco Pais, 1096 Lisboa Codex 


\section{Euchem-Surface Forces in Science and Technology}

A capital sueca, Estocolmo, é o palco escolhido para a conferência "Surface Forces in Science and Technology", organizada pelo Comité Nacional Sueco para a Quimica e com data marcada para os dias 15, 16 e 17 de Junho do próximo ano. A conferência cobre os mais recentes progressos no estudo das inte- racçōes moleculares, nos seus aspectos experimentais e teóri$\cos$.

Toda a correspondência relativa ao encontro científico deve ser enviada para: The Swedish Committee for Chemistry, Wallingatan $243 \mathrm{tr}$, S-111 24 Stockholm (tel. 46-8-115280; fax. 46-8-106678).

\section{$11^{\circ}$ Congresso internacional sobre catálise}

Entre 30 de Junho e 5 de Julho de 1996 decorre em Baltimore, Maryland, nos Estados Unidos, $011^{\circ}$. Congresso Internacional de Catálise, organizado pela Sociedade de Catálise da América do Norte. Os organizadores do evento querem privilegiar comunicações que descrevam novas aplicações da catálise industrial e avanços na preparação e caracterização de catalisadores. Autores e investigadores interessados podem contactar $\mathrm{Dr}$. Kathleen C. Taylor, Physical Chemistry Department, General Motors NAO R\&D Center, 30500 Mound Road, Warren, MI, 4809-9055 USA (tel. 1-810-986-8697); E-mail: KTAYLOR a CMSA. GMR. COM

\section{Tecnologia limpa em Maui e Lisboa}

Peritos europeus participam entre 16 e 20 de Outubro próximo na conferência do Pacíico sobre "Controle Ambiental do Processo de Combustão". 0 evento decorre em Maui, Hawai. Os representantes europeus apresentarão um documento sobre 0 programa europeu R\&D de tecnologias de carvão limpas, e preparam-se para negociar a participação da Austrália e do Canadá no referido programa.

Os resultados finais do programa têm apresentação decorrerá em Lisboa nos dias 28 e 29 de Novembro deste ano, e onde se procederá à análise $\mathrm{e}$ discussão do programa, bem como a matérias especificas no domínio do uso combinado da biomassa ou outros desperdicios com carvão de pedra para produzir energia amiga do ambiente. Na capital portuguesa discutemse ainda processos alternativos de abordagem a estas questōes $\mathrm{e}$ implicaçōes tecno-económicas.

Mais informações disponiveis sobre a conferência de Maui através de European Commission, DG XII/F3, Mr. J. M. Bemtgen, 200 rue de la Loi, B1049 Brussels (tel. 32-22962071; fax.32-2-2964288). Para contactos sobre a conferência de Lisboa, os interessados deem contactar em Bruxelas ou em Lisboa para o Instituto Superior Técnico, departamento de Engenharia Mecânica, Prof? ${ }^{3}$. Maria Graça Carvalho, Av. Rovisco Pais, P-1096 Lisboa Codex (tel.351-1-8417372; fax 351-1-8475545)

\section{Seminários Agostinho L o u r enço}

A partir de Novembro deste ano, realizar-se-ão com periodicidade aproximadamente mensal os Seminários Agostinho Lourenço. Estes seminários, organizados pelo Departamento de Quimica e Bioquímica da Faculdade de Ciências da Universidade de Lisboa, são dirigidos a docentes, investigadores e alunos, com o objectivo de divulgar com profundidade, mas de forma a serem entendidos por não especialistas, os trabaIhos de investigação de cientis-

tas nacionais e estrangeiros da área da Química e Bioquímica. 0 programa para 1995 será oportunamente divulgado. Em 1994 serāo realizados dois seminárioS: "A energia das moléculas" por José Artur Martinho Simões (FCUL), no dia 23 de Novembro, e "Introdução sistemática de assimetria e flexibilidade electrónica: contribuição para o controle da reactividade dos metalocenos de Mo e W" por Carlos C. Romão (IST e ITBQ), no dia 14 de Dezembro.

\section{Europa e Japão colaboram na ciência}

A Europa e o Japão mantêm actualmente um importante programa de cooperação científica em diversos fóruns internacionais. Em Outubro de 93 foi criado 0 Fórum Euro-Japonês da Ciência e da Tecnologia, mas a cooperação tem-se desenvolvido sobretudo no campo da fusão termonuclear, da biologia, na produção de sistemas industriais, energia e ambiente.

Desde 1988, a Uniāo Europeia e 0 Japão, juntamente com Estados Unidos e Rússia, colaboram no reactor nuclear experimental internacional ITER e no programa de pesquisa japonês de energia atómica JAERI.
No campo da biologia, europeus e japoneses estão empenhados no Programa Ciência Fronteira Humana (HFSP), que desenvolve trabalho no âmbito da pesquisa cerebral, dos mecanismos moleculares e das funções biológicas.

Energia e ambiente são igualmente áreas de colaboração. Cientistas dos dois continentes estudam actualmente medidas tendentes a minimizar 0 impacto do $\mathrm{CO}_{2}$ e os processos de combustão. Além disso, promovem intercâmbio de investigadores entre instituições universitárias, institutos nacionais e laboratórios da indústria.

\section{Energia para 0 futuro}

A Comissão Europeia publicou no âmbito do JET (Joint European Torus) um relatório sobre a fusão nuclear intitulado "Fusão Nuclear: Energia para os Séculos Futuros". 0 documento inclui informação detalhada sobre a fusão nuclear, o balanço das realizações do JET e a sua relação com o programa europeu de fusão.

0 JET é o maior experimento nuclear mundial, produto do entendimento entre os Doze, a Suécia e a Suiça. 0 seu principal objectivo é obter um estudo do plasma em condições o mais aproximadas possivel das necessárias num reactor termonuclear.

Os interessados em obter uma cópia do relatório devem contactar o Office for Official Publications of the European Commmunities, 2 Rue Mercier, L-2985 Luxembourg (tel. 352499281; fax 352-488573). Para mais informações sobre o JET devem contactar: Public Relations Group, JET Joint Undertaking, Abingdon 0X14 3EA, United Kingdom. 


\section{Pharmaceutical applications of NIR spectroscopy}

A Sociedade Sueca de Química e a Academia Sueca de Ciências Farmacêuticas realizam entre 13 e 15 de Junho de 1996, em Estocolmo, a conferência NIR Spectroscopy, que decorrerá em conjunto com a conferência nacional "Analytical Days", usualmente frequentada por cerca de 700 analistas químicos suecos. Mais informação pode ser pedida para The Swedish Chemical Society, Wallingatan 24, 3tr, S-111 24 Stockholm, Sweden (tel. 4684115260; fax. 468106678).

\section{Euroanalysis IX \\ B ol onha, Setembro 96}

Entre 1 e 7 de Setembro de 96 , realiza-se na cidade italiana de Bolonha a conferência trienal de química analítica Euroanalysis, organizada pelo grupo de trabalho em química analítica da Federação das Sociedades de Química Europeias e pela divisão de química analítica da Sociedade Italiana de Química. A Euroanalysis apresenta um programa cientifico variado que pretende abarcar todas as áreas da química analítica. Os organizadores sugerem tópicos no campo da educação, validação em química analítica, materiais de referência, etc.

Para assegurar a mais alta qualidade cientifica, as comunicações propostas serão avaliadas por um painel internacional. 0 inglês é a língua oficial da conferência e não será feita tradução simultânea.

Os organizadores disponibilizaram acomodaçōes em hotéis $e$ ainda uma rede de quartos de baixo custo cedidos em colégios da cidade italiana medieval.

Os contactos por correio ou fax devem ser feitos para Prof. L. Sabbatini, Euroanalysis IX, Dipartimento de Chimica, Università di Bari, Via Orabona, 4, 7016 Bari (Italy) (tel. 39-80-242020/16/14; fax 39-80-242026)

\section{Curso de Química 0ceanográfica 1994-95}

O curso de Química Oceanográfica, à distância, é dirigido a licenciados em faculdades experimentais e decorre entre 1 de Dezembro deste ano e 20 de Maio de 95. A avaliação curricular será feita em quatro momentos (à distância) e inclui a redacção de um trabalho monográfico, um trabalho experimental em centro contactado pelo aluno perto da

\section{Euro Abstracts}

i n f or m a çã 0 d i s p o n íve I

A União Europeia prossegue com a sua politica de informação e apoio a projectos de investigação e de desenvolvimento tecnológico nos Estados membros. Os projectos, organizados com base nos programas estruturais previamente delineados, definem as áreas onde a investigação se concentra.

Mas, para além disto, as actividades cientificas e técnicas da UE incluem investigações sobre carvão e aço, doenças profissionais, segurança, ambiente, tecnologia das novas energias, bem como medidas de promoção da transferência de inovações e tecnologia e acções tendentes a reforçar o mercado comunitário da informação.

Por conseguinte, os programas de investigação proporcionam um largo número de publicações - relatórios técnicos e científicos, sumários dos resultados dos projectos, actas de conferên- cias, directórios científicos, últimas recensões sobre determinadas áreas científicas e técnicas, bem como informações de carácter mais genérico.

Nesta área se incluem os Euro Abstracts, publicação mensal editada pela DG XIII, que fornece resumos e dados bibliográficos das publicações existentes e indicação das línguas em que estão disponiveis.

Trata-se pois de um bom auxiliar para a indústria e para todos aqueles que se dedicam ou interessam pela ciência. Pode ser adquirido nos agentes de venda de UE mediante uma assinatura de 60 ecus ou avulso (5 ecus), ou directamente pedido ao departamento de publicações Oficiais, 2 Rue de Mercier, L -2985, Luxemburgo. 0 Euro Abstracts está também disponivel no serviço "on line" gratuito, "RTD Publications", através do CORDIS no ECHO.

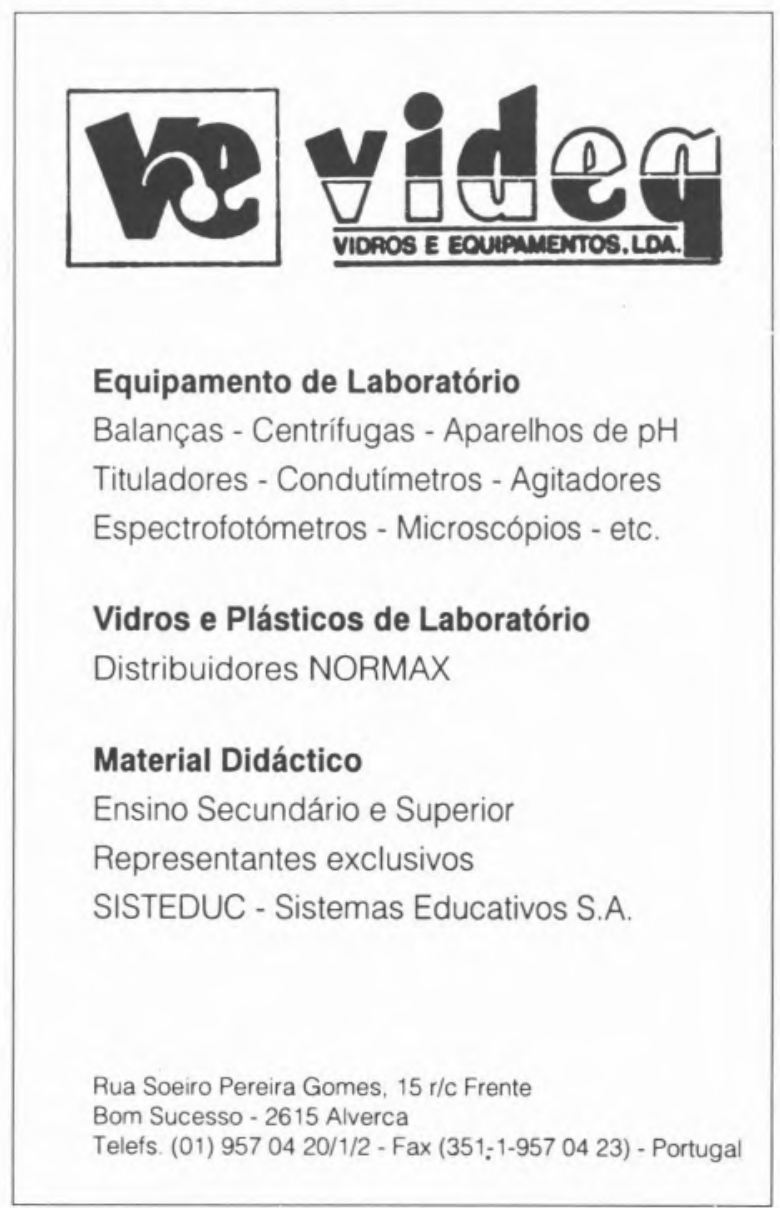

\begin{abstract}
provas receberá o diploma outorgado pelo Centro da Universidade À Distância de Cádis. Os interessados podem solicitar informação na Secretaria del Centro UNED, Plaza de San António, 2, 1102 Cádis, Espanha (tel. 956-212303; fax. 212306).

sua área de residência, e um exame final, este presencial, no mesmo centro. Quem superar as
\end{abstract}




\section{Resíduos Industriais em Portugal}

Até final do século, Portugal produzirá entre 10 e 15 milhões de toneladas de resíduos industriais. produz mais cerca de 1,4 milhões de toneladas. Uma grande parte tem como destino os solos ou as lixeiras a céu aberto. Desde 1986. o quantitativo de lixos produzidos cresceu $30 \%$, embora a tendência não tenha confirmado os esperados dois milhões de toneladas anuais previstas para 95 . Muitas toneladas de resíduos que precisam de selecção, tratamento e em alguns casos destruição sanitária.

0 dificil quadro, resultante de décadas de indecisão e falta de planeamento estratégico ambiental, resultou agora no impasse político para decidir onde montar o sistema destinado a tratar. armazenar e incinerar pouco mais de $10 \%$ do total dos lixos da indústria.

Actualmente, alguns residuos são controlados, sobretudo
Todos os anos a indústria

os provenientes da indústria extractiva-em clara regressão devido ao fecho de 30 minas desde 1986 - depositados em condiçōes controladas, e uma parte dos residuos da produção eléctrica, enviados para aterros já existentes e para a indústria cimenteira que os incorpora na fabricação de cimento. A indústria transformadora, com uma tradição de descarga no solo dispõe também de estações de tratamento e aterros para recepção de lamas, desperdícios de curtumes e outros resíduos sólidos.

No final deste ano, o Estado propõe-se tomar a decisão sobre os locais onde construir o sistema de tratamento centalizado, constituído por uma central com uma unidade de incineração e outra de tratamento físico-quimico, uma estação de transferência e dois aterros controlados. 0 processo vem sendo discutido de forma alargada no seio do Forum do Sistema Integrado, uma espé-

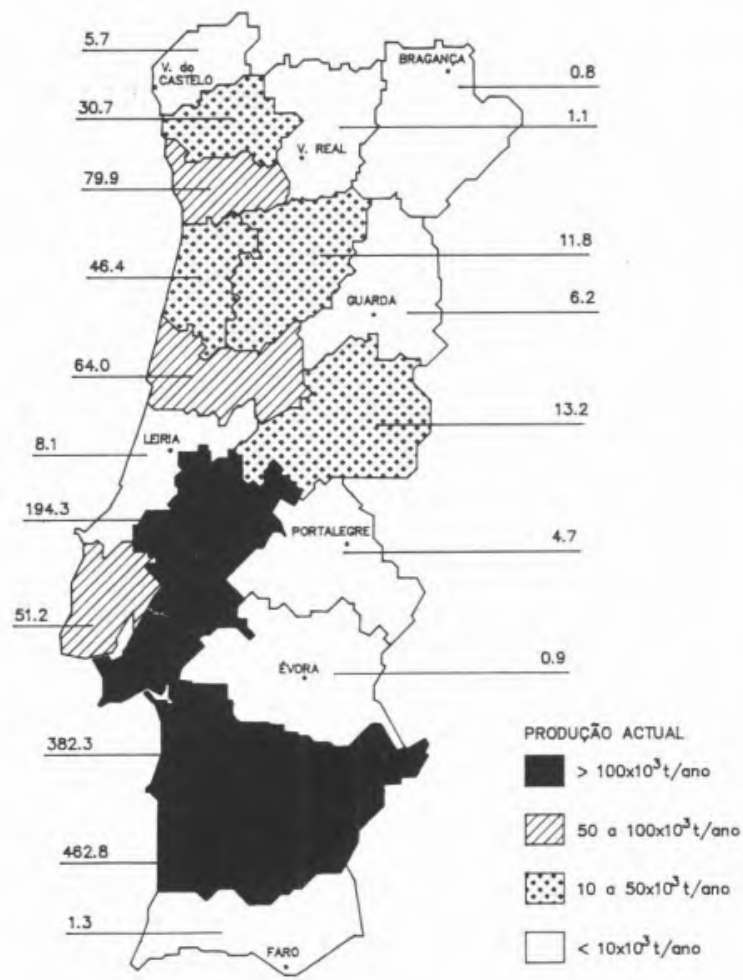

PRODUÇÃO ACTUAL DE RESIDUOS PERIGOSOS POR DISTRITO ( $t /$ ono) cie de câmara de debate em que se sentam departamentos governamentäis, associações ambientais, autarquias e técnicos do ambiente.

À semelhança da Dinamarca e da Finlândia, paises que preferiram sistemas centralizados, também em Portugal os técnicos consideram essa solução mais adequada para limitar o número de unidades,assegurando ao mesmo tempo um maior controle do equipamento e funcionamento a todos os niveis, incluindo 0 factor humano. Isto, se excluirmos 0 peso do critério económico, que concorreu igualmente para a opção centralizada, $25 \%$ mais barata do que uma alternativa que incluiria duas centrais de tratamento. No caso dos aterros, os cálculos estatais sustentam o contrário, ou seja, os menores custos associados ao transporte para dois aterros, um no norte e outro no sul do país, compensarão os sobrecustos do investimento $e$ dos encargos de exploração associados ao desdobramento.

Os potenciais locais foram definidos tendo em conta a distribuição geográfica dos resíduos, filosofia racional que os próprios técnicos independentes defendem.

Depois de estabelecido o princípio, os técnicos definiram zonas de macrolocalização. Neste caso, os eixos Setúbal-Lisboa e Porto-Aveiro surgem como os mais sérios candidatos e albergar a incineradora e os aterros. Beja é 0 maior produtor nacional de resíduos, devido às minas de Neves Corvo. No seu conjunto, o distrito de Setúbal tem $42 \%$ da produção de lixos industriais e é o maior produtor de lixos da indústria transformadora.

Mas o mais difícil será certamente a escolha do local exacto. Os estudos de Iocalização apontam Setúbal, Estarreja e Aveiro como locais de preferência, uma vez que têm já infraestruturas montadas, uma importante zona industrial e uma menor densidade populacional.

\section{RACIONALIDADE E QUIMIOFOBIA}

Porém, em todos os locais seleccionados depois dos respectivos estudos geográficos, as populações vieram para a rua manifestar o que alguns especialistas já chamam a quimiofobia. Paralisaram estradas, boicotaram eleições, ameaçam fazer greves colectivas e jornadas sistemáticas de desobediência civil, ignorando as razões pragmáticas dos técnicos ou sequer a urgência ecológica dos políticos.

Em 12 locais seleccionados para instalar a central incineradora não houve acordo da população em nenhum. Apenas protestos e negativas rotundas. Em Sines já foi criada uma "comissão de luta contra a instalação da incineradora", com base no "perigo de destruição do turismo, da pesca e da natureza", e a cidade ameaçou uma "greve verde". Em Colmeias, Leiria, os habitantes, com 0 apoio da autarquia, boicotaram as eleições para o Parlamento Europeu. Em Grândola, 0 próprio PSD local apoiou a oposição a um eventual aterro. No Seixal, o presidente da Câmara avisou que não permitiria que Ihe estragassem o Plano Director Municipal". Na Bobadela, Loures, em Estarreja, em Oliveira do Bairro e em Setúbal, o cenário repetiu-se.

De qualquer forma, a tecnologia utilizada prevê um rigoroso controle de segurança destinado a mitigar os riscos inerentes da tecnologia e do factor humano. A incineradora e o tratamento fisico-químico empregam vários sistemas de controle, comando e monitoração e os reservatórios de residuos liquidos estão equipados com sistemas de ventilação, sistemas contra incêndio, blocagem do betão, etc. Ou seja, o conjunto dos sistemas de segurança deveria alimentar um principio de racionalidade nas populações e responder às inquietações da quimiofobia.

A subdirectora geral do Ambiente, Almerinda Antas, como 
de resto a maioria dos técnicos governamentais, considera estes receios "infundados e inexplicáveis". "As pessoas fazem o paralelismo entre os residuos industriais e os residuos radioactivos. Nós não temos energia nuclear. Em Portugal consumimos e produzimos menos matérias primas perigosas. São residuos que contêm componentes perigosos muito diminutos em relação à matéria-prima utilizada. Com 0 sistema integrado vamos exigir dos industriais uma caracterização exaustiva sobre os componentes dos resíduos que produzem. Será a própria indústria a embalá-los e obrigada fornecer informaçōes rigorosas".

No entanto, nem os spots de desenhos animados exibidos na televisão, nem o conceito da "fábrica transparente", que configura uma participação alargada à comunidade na administração da central incineradora, conseguiram convencer as populações. Nenhuma explicação técnica conseguiu ultrapassar 0 medo. 0 mesmo medo alimentado pela tradicional inadequação entre indústria $e$ meio-ambiente e por décadas de descarga indiscriminada nos rios e nas lixeiras. Além disso, existe um problema político de fundo, isto é, nenhum presidente de câmara que apoie a instalação do aterro ou da central incineradora será reeleito. Portanto, os políti- cos têm um problema, e os técnicos têm o problema dos políticos. Na pior das hipóteses, o Governo pode ver-se obrigado a construir uma central incineradora sob vigilância da GNR.

\section{QUEIMA E TRATAMENTO Físıco-Químico}

A unidade de incineração, a instalar no centro-sul do país terá acoplada uma unidade para tratamento físico-químico e ocupa uma área previsivel de 8 ha, incluindo área de armazenagem $e$ infraestruturas.

A incineração é considerada a melhor solução para tratar lixos, embora alguns residuos. sobretudo os de alto teor em água, não contenham poder calorífico suficiente e como tal sejam encaminhados para outros processos. De qualquer forma, os remanescentes dos processos de tratamento terão como destino final 0 aterro controlado.

Para a queima seguem apenas 37 mil toneladas anuais de residuos liquidos sólidos ou pastosos (emulsōes de óleos usados, residuos orgânicos e soluções ácidas com metais pesados. residuos do comércio e serviços, fibras sintéticas, óleos e gorduras, entre outros) produzidos na sua maioria nos distritos de Setúbal, Lisboa e Porto. De fora ficam resíduos radioactivos, substânci-

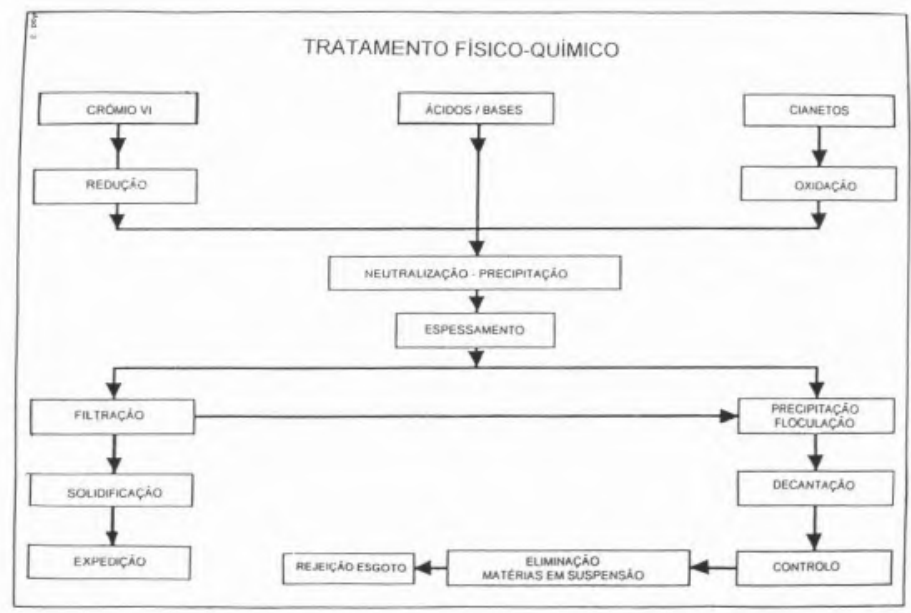

as explosivas, os PCB, os residuos com riscos patogénicos e os solventes e pesticidas com alta incorporação de cloro.

A aceitação dos lixos prevê análises prévias para estabelecer o chamado "relatório prévio do perfil do residuo", uma ficha sobre as suas propriedades físioquímicas, sobre o processo de produção, o poder calorífico, o ponto de inflamação, etc... É esta ficha que estabelece 0 destino, 0 método de tratamento e de armazenagem e o transporte adequado. Para evitar qualquer alteração entre a amostra inicial e a carga enviada, o carregamento será submetido a análise de controle.

0 proceso de combustão efectua-se num forno rotativo com um tempo de retenção entre 1100 graus celsius. As escórias

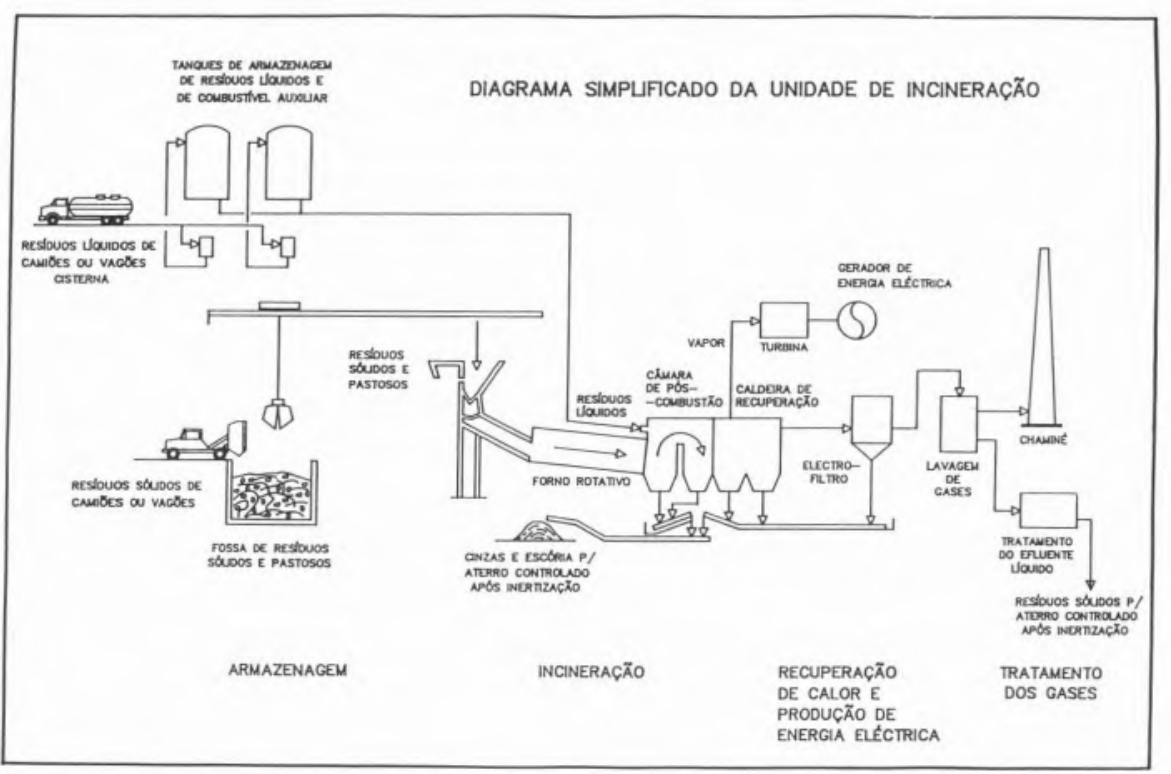

uma e quatro horas, e cuja eficiência destrutiva de compostos orgânicos atinge, segundo os técnicos, 99,99\% de eficácia.

Uma câmara de pós-combustão permite arrefecer e purificar os gases, que saem a mais de são recolhidas e transportadas para uma fossa de betão, acondicionadas em contentores e depois transferidas para 0 aterro.

0 complexo inclui uma unidade de tratamento físico-quimico destinada a 16 mil toneladas anuais de residuos inorgâni$\cos$, minerais, aquosos ou sólidos vindos de sectores como a indústria química e a metalomecânica. Pesados, analisados e armazenados em reservatórios para 0 efeito, no caso das lamas, e em tambores e fossas no caso dos sólidos, antes de serem solidificados e enviados para aterro sofrem então um tratamento que visa reduzir certos compostos, como por exemplo os cromatos. muito tóxicos e presentes nos efluentes dos banhos de cromagem.

Os efluentes gerados neste processo são eles próprios tratados e controlados antes de serem lançados no colector geral ou na rede de drenagem independente.

0 modelo de incineradora escolhido pelo governo foi criticado por a tecnologia seleccionada não estar preparada para queimar residuos de compostos clorados (OS PCB e os solventes clorados ou outros compostos com cloro). Agentes tóxicos de grande 
estabilidade química e baixa volatilidade, perigosos para o homem, os PCB (policlorobifenilos) são aplicados nos fluidos de aquecimento dos transformadores eléctricos e actualmente exportados para Inglaterra. A responsável governamental Almerinda Antas considera que "Portugal tem um quantitativo de PCB muito diminuto para eliminar e por isso era injustificado construir uma unidade mais cara. Se Portugal investisse numa central de tratamento desse tipo, em pouco tempo esgotaria os seus próprios residuos, ficando aberto à importação de resíduos alheios".

Portugal exportou em 92 para aterros ingleses e para incineração em centrais francesas $e$ britânicas quase meia tonelada de resíduos perigosos (solventes com mais de $5 \%$ de cloro, lamas e PCB), uma quantidade quatro vezes menor do que a exportada em 1990

\section{ATERROS}

Dois aterros controlados completam o sistema. Muito provavelmente, um será construído no Norte e o outro no Centro-Sul do país. Em traços muito gerais, um aterro controlado é um local drenado de armazenagem de resíduos acondicionados em camadas que vão sendo cobertas. 0 estudo técnico recomenda a "deposição em extensão", ou seja, a criação de células de deposição diária, demarcadas em função da quantidade diária de resíduos. Estes sectores diários interligam-se até ocuparem a extensão de área a aterrar, formando um primeiro estrato que depois de coberto será sobreposto com 0 estrato seguinte.

Com uma área prevista de 8 a 10 hectares, 10 metros de profundidade e um prazo de vida útil de seis anos, 0 aterro é forrado com uma membrana impermeável sintética em polietileno de alta densidade, com uma espessura variável entre 1,2 e 2,5 mm, protegida superior $e$ inferiormente por geotêxtil não tecido, um material que protege a membrana de risco de perfuração.

Um sistema de drenagem evita que as chamadas águas de lixiviação, pluviais ou outras, se possam infiltrar nos solos.

Todos os resíduos que entrem no sistema acabam no aterro, incluindo as cinzas volantes resultantes da incineração e os residuos submetidos a tratamento físico-químico. Prevê-se que estes aterros recebam anualmente cerca de 145 mil toneladas de resíduos. Alguns liquidos, substâncias explosivas, oxidantes ou inflamáveis, residuos infecciosos hospitalares ou embalagens contaminadas não são admitidos.

No fim da sua vida útil, 0 aterro é selado e a área de superficie impermeabilizada, recoberta com geotela e material drenante. aterrada e revegetada. Os equipamentos de apoio à exploração são desmantelados e a qualidade das águas de superfície e subterrâneas monitoradas regularmente.

A escolha do local é também 0 mais problemático neste caso, apesar de existirem zonas que se aproximam dos critérios geográficos ponderados (baixo coeficiente de permeabilidade dos solos, distância de linhas de água de consumo ou subterrâneas. visibilidade, isolamento de zonas habitadas e afastado de falhas sísmicas activas ou prováveis, do risco de cheias ou pluviosidade, entre outros aspectos). No entanto, o estudo de alternativas do sistema prevê já a dificuldade de encontrar o sítio ideal, e muito provavelmente os técnicos terão que contentar-se com o "mal menor". No entanto, novas normas sobre aterros, em preparação na UE, poderão vir a fazer rever os projectos existentes.

Carlos Alberto Saraiva MAGNETROM

\title{
Desde 1967
}

\section{Anos ao Serviço da Investigação e Indústria}

\author{
Aparelhagem de Instrumentação e Controlo \\ Equipamento de Aquisição e Controlo \\ Representantes exclusivos da \\ $E G \& G$ / PAR
}

MAGNETROM - COMÉRCIO E INDÚSTRIA DE APARELHAGEM ELÉCTRICA, S.A.

Rua Fialho de Almeida, 5-2ํㅡ. Dt. -1000 LISBOA

Tel. 3871918

Fax. 3874773 


\section{European Communities Chemistry Council Annual Report}

Two meetings were held during the year, in May in Brussels at the offices of the Commission of the European Communities, and in October at the University of Venice by invitation of the Italian Chemical Society.

Mr E. J. de Ryck van der Gracht (Royal Netherlands Chemical Society) continued as Chairman and Dr J. S. Gow (Royal Society of Chemistry) as ViceChairman. The Secretariat was administered by the Royal Society of Chemistry, with Ms E.K. McEwan as Secretary. Professor F. Alderweireldt (Flemish Chemical Society) continued as Chairman of the Council's European Chemist Registration Board, Secretariat of which was administered by the Royal Society of Chemistry, with Mrs A. Bennett as Secretary.

At the end of the year there were 23 societies from 14 countries in membership. Following the agreement between the European Community member states and EFTA countries to establish a European Economic Area, national chemical societies in EFTA countries were invited to become members of the Council and to participate in its activities.

In June, a paper Community Support for R\&TD in Chemical Sciences and Technologies was published in collaboration with CERC3 (Chairmen of the European Research Councils Chemistry Committee), COST (European Cooperation in the field of
Scientific and Technical Research: Technical Committee on Chemistry), EFCE (European Federation of Chemical Engineering), and CEFIC (European Chemical Industry Council). The Council also published in June a report Chemistry for a Clean World to elaborate certain issues raised in its earlier report Chemical Science and Technology: European Needs for the 1990s.

Two meetings of the European Chemist Registration Board were held during the year to consider applications submitted by the National Assessment Panels of participating member societies for the award of the designation 'European Chemist'. At the end of the year there were a total of 226 European Chemists, successful candidates being members of societies in Belgium (20), Denmark (2), France (2), Ireland (13), Italy (6), The Netherlands (17), Portugal (3), Spain (46) and the United Kingdom (117). All are entitled to use the designatory letters 'EurChem'. The Council continued to update its schedules of qualifications which provide a guide to the comparability of chemistry qualifications at three different levels.

The Council was represented by Professor F. Alderweireldt at the European Science Summit in Brussels in October. Links were maintained with the Federation of European Chemical Societies, the President, Dr R. Darms, being invited to participate in the Coun- cil's meetings.

Note:

The European Communities Chemistry Council (ECCC) was founded in 1973 with its primary object being:

To act in an advisory or representative capacity in matters relating to the science and practice of chemistry'

It comprises national societies, both learned societies and those with a membership of industrial chemists. The member societies represent a total of some 150,000 academic, industrial and government chemists.

\section{Member Societies}

The names of participating societies are given below:

BELGIUM: Societe Royale de Chimie, Koninklijke Vlaamse Chemische Vereniging, FabechimVebevevchem;

DENMARK: Danish Chemical Society, Dansk Ingeniorforening, Kemiingeniorgruppen;

FINLAND: Association of Finnish Chemical Societies:

FRANCE: Societé Française de Chimie, Union Nationale des Associations, Françaises d'Ingenieurs Chimistes (UNAFIC);

GERMANY: Gesellschaft Deutscher Chemiker, DECHEMA Deutsche Gesellschaft fur Chemisches Appartewesen, Verband angestellter Akademiker und lei- tender Angestellter der Chemischen Industria $\mathrm{eV}$;

GREECE: Association of Greek Chemists:

IRELAND: Institute of Chemistry of Ireland;

ITALY: Societa Chimica Italiana, Consiglio Nazionale dei Chimica;

LUXEMBOURG: Association de Chimistes Luxembourgeois;

NETHERLANDS: Koninklijke Nederlandse Chemische Vereniging;

NORWAY: Norwegian Chemical Society;

PORTUGAL: Sociedade Portuguesa de Quimica;

SPAIN: Real Sociedad Española de Quimica, Asociacion Nacional de Quimicos de España (ANQUE). Consejo General de Colégios;

UNITED KINGDOM: Royal Society of Chemistry,

Representatives of the following bodies are invited to participate:

- Federation of European Chemical Societies (FECS),

- European Chemical Industry Council (CEFIC),

- Chairmen of the European Research Councils Chemistry Committee (CERC3).

\section{Q u i m i tec 94}

A Quimitec'94, $1^{\text {a }}$ Feira da Química Aplicada, do Plástico e da Borracha, realizou-se de 22 a 25 de Junho de 1994, nas instalações da EXPONOR/Feira Internacional do Porto, tendo sido organizada pela Associação Industrial Portuense, com a colaboração da Delegação do Porto da SPQ (entre outras entidades).
Na QUIMITEC participaram 105 expositores, tendo-se contabilizado um total de 5.259 visitantes. A SPQ participou com um stand próprio, no qual se fez a apresentação do Clube de Software da SPQ (a cargo de J.P. Leal), e organizou um ciclo de palestras que decorreram nos dias 22 e 23 de Junho, nomeadamente:
- Automatização Laboratorial, J.L. Costa Lima, Fac. Farmácia da U.P.

- Validação de Métodos Analiticos, Maria Arminda Alves, Fac. Engenharia da U.P.

- Borracha - Um referencial do Desenvolvimento Industrial, M. Caetano, Polimeros do Ave, SA
- Operação de Processos Industriais Assistida por Computador, S. Feyo de Azevedo, Fac. Engenharia da U.P.

A próxima edição de QUIMITEC está prevista para 1996.

J.L. Figueiredo 